\title{
The hierarchical model of la-la-la role in campus culture construction
}

\author{
Lu Liu ${ }^{1}$, Feng Li $^{1}$, Qiaohui Wang ${ }^{2}$, Kunling Qin ${ }^{3}$, Qiongqiong Hu${ }^{4}$, Qian Yang ${ }^{1}$, Yanni Liu ${ }^{1}$ and Bing Zhang ${ }^{1, a}$ \\ ${ }^{1}$ Institute of Physical Education, Huanggang Normal University, Huangzhou 438000, China \\ ${ }^{2}$ Macaomiao Primary School, Tuanfeng 438000, China \\ ${ }^{3}$ Yidu Gaobazhou Middle School, Yidu 443300, China \\ ${ }^{4}$ Fangxian Mengu Middle School, Shiyan 442108, China
}

\begin{abstract}
La-la-la operating in the construction of colleges and universities has a great value, can promote the students' physical and mental health, colleagues to promote the construction of campus culture, different ways of la-la-la operating organization implement and carry out on all aspects of the role is not the same. Solutions are mainly in the colleges and universities to build operation association, organization propaganda, carry out la-la-la operating activities to promote and enhance the campus spiritual civilization construction and strengthen students' self-confidence and moral quality. Based on the AHP method to study la-la-la hold different organization form for the role of the campus culture construction, and to quantify value, said the results. The school should take the classroom education is complementary, held mainly operating activities stimulate la-la-la fuck role in campus culture construction.
\end{abstract}

\section{Introduction}

Cheerleading is originated from America; China develops domestic cheerleading activities by referencing American experiences in cheerleading. Cheerleading combines with aerobics, yoga, gymnastics and others features, and has its own unique clothing and movement features. Due to started late in cheerleading, China shows backwardness in cheerleading arrangement, music matching and clothing selection. Cheerleading culture has inseparable relations with universities campus culture; the two complement one another and pursue common development. Cheerleading cultural values on universities, lots of scholars have made a great deal of researches [1-3].

Among them, $\mathrm{Xu}$ Xiao-Gang further analyzed cheerleading values in campus sports culture construction on the basis of referencing American researches, result thought cheerleading had important effects on establishing positive university sports teaching forms, and was beneficial to students' physical and psychological health [4]. Ren Xiao-Feng and others in researching cheerleading effects on universities sports culture, they pointed out campus culture and cheerleading culture reinforced each other, and the two helped each other forward [5]. Zhou Ling by analyzing Cheerleading and campus culture effects, she thought that cheerleading could propel to campus cultural construction.

With formers basis, the paper makes reasonable defining hierarchical structure in analytic hierarchy process method by researching on campus culture and cheerleading culture function mechanism, and gets research results by making quantitative analysis of judgment matrix impacts on different schemes and different aspects campus cultures. It provides suggestions and references for cheerleading and campus cultural construction.

\section{Cheerleading culture}

Cheerleading actually is during the situation with music as background athletes wearing specific various beautiful clothes to carry on complete set of movements accompanying by music rhythm. The event is in team cooperative form, it requires having higher team awareness.

Table 1. Culture construction effects table

\begin{tabular}{|c|c|}
\hline Cheerleading culture & Campus culture \\
\hline Promote spiritual civilization & $\begin{array}{c}\text { Improve students' ethical } \\
\text { standard }\end{array}$ \\
\hline Enrich spare time life & $\begin{array}{c}\text { Promote school spiritual } \\
\text { civilization } \\
\text { literacy }\end{array}$ \\
\hline $\begin{array}{c}\text { Enhance students' cultural } \\
\text { confidence }\end{array}$ & $\begin{array}{c}\text { Cultivate students' aesthetic } \\
\text { awareness }\end{array}$ \\
\hline Improve ethical standard
\end{tabular}

Cheerleading divides into technical cheerleading and dance cheerleading. Research shows that cheerleading has important promotions in setting up hard struggle spirits, cultural attainments, aesthetic awareness as well as confidence aspects. And campus culture interweaves with that. So cheerleading organizing will surely have impacts

a Corresponding author: tiyuxi@qq.com 
on campus culture. Cheerleading culture and campus culture effects table are showed as Table 1 .

\section{Analytic hierarchy process method}

American famous scholar Saaty proposed a kind of quantitative and qualitative, subjective and objective combined system hierarchical mathematical analysis method in the seventies of last century that is AHP [6]. The core of the algorithm is weights calculating. It specially fits for multiple targets problems, complex system decision-making problems, is a powerful mathematical method to convert problems into quantitative research. Its features are simple thought, well arranged, broad applying range and so on; nowadays analytic hierarchy process has already been widely spread in each field for solving practical problems. Analytic hierarchy process method procedures are mainly as three procedures. Those are establishing hierarchical structure, construct judgment matrix, hierarchical arrangement and consistency test.

\section{Step-1 Hierarchical structure establishment}

In analytic hierarchy process, hierarchical structure generally has three layers, target layer(S)that is final target or final expected result in problem solving, criterion layer $\left(f_{m} \quad\right)$ that is requirement and criterion to complete problem, criterion layer can be one layer and also can be multiple layers, scheme layer $\left(p_{n}\right)$ that is all methods to solve the problems. Calculate scheme layer different schemes weights and ranks, defines best scheme. Generally, in practical problems, it selects maximum weight scheme as best scheme.

\section{Step-2 Construct judgment matrix}

In hierarchical structure, assume the next layer has $\mathrm{n}$ pieces of factor $C=\left(C_{1}, C_{2}, \cdots C_{n}\right)$ that causes impacts on previous layer target or criterion, all factors carry out paired comparison, express comparison result with quantization values, for example $C_{i}, C_{j}$ importance comparison structure is using $a_{i j}$ to express, and then all factors carry out comparison and then can get judgment matrix A .Its expression is as following.

Among them, $a_{i j}$ value is respective expressed by 1 9 numbers and their reciprocals, after Saaty researching, it is thought that using 1 9 scale to express comparison structure conforms to people judgment ability in psychology.

\section{Step-3 Consistency test and weight vector calculation}

Consistency matrix definition: to matrix $A=\left(a_{i j}\right)_{n^{*} n}$, if elements in matrix meet $a_{i j} a_{j k}=a_{i k}$, then matrix is consistent matrix. Among them, $a_{i j}>0, a_{i j}=1 / a_{j i}$. In order to use it to calculate factors weights, it only requires matrix inconsistency within permissible condition. When problems are relative complex, we cannot take all factors into consideration, which causes judgment matrix cannot arrive at consistency in ideal state when carry out paired comparison to construct judgment matrix [7].

Judgment matrix consistency indicator $C I$, and judgment matrix consistency rate $C R$, its computational method is as following formula shows: $C I=\frac{\lambda_{\max }-n}{n-1}$.

Among them, $n$ represents judgment matrix order number, that is also the number of comparison factors, $C R=\frac{C I}{R I}$

When $C R \geq 0.1$, it is thought that judgment matrix appear inconsistency and needs to adjust judgment matrix again. When $C R<0.1$, judgment matrix inconsistency is within acceptance range, it can go ahead with next step calculation. Further calculate hierarchical total arrangement and combination consistency test.

Assume in layer $\mathrm{A}$ that $\mathrm{m}$ pieces of factors values computational result is $\alpha_{m}$, corresponding consistency indicator value is respectively $C I_{m}$, in next layer $\mathrm{B}, \mathrm{n}$ pieces of factors to layer A computational weight is $\beta_{n m}$, then layer $B$ factors total arrangement weight is: $w_{i}=\sum_{j=1}^{m} \alpha_{i} \beta_{i j}$.

Combination consistency test consistency ratio is:

$C R=\frac{\sum_{j=1}^{m} \alpha_{j} C I_{j}}{\sum_{j=1}^{m} \alpha_{j} R I_{j}}$

Weight calculation. Calculate judgment matrix weight vector has many methods such as definition calculation, computer iteration, power method and harmonization method, from which the relative simple one is harmonization method. Assume judgment matrix an piece of factors weight $\mathrm{s}$ weight vector is as following: $W=\left(w_{1}, w_{2}, w_{3} \cdots w_{n}\right)$

\section{Cheerleading analytic hierarchy process}

According to cheerleading effects and campus cultural construction, it establishes hierarchical structure, top layer: Cheerleading form of education. Criterion layer is improving ethical standards $f_{1}$ promoting spiritual civilization $f_{2}$ literacy training $f_{3}$ develop self-confidence and fighting spirit $f_{4}$. Scheme layer divides into classroom language teaching $p_{1}$ cheerleading association established $p_{2}$ cheerleading organized activities $p_{3}$.

Similarly according to harmonization method's computational method respectively compute matrix weight vector, maximum feature value and consistency indicators. 
Combined weights rank is as following Table 2. By testing, matrix and combination consistency test conform to requirements.

Table 2. Weights total arrangement.

\begin{tabular}{|c|c|c|c|c|c|}
\hline \multirow{2}{*}{$\begin{array}{c}\text { Hierar } \\
\text { chy }\end{array}$} & $f_{1}$ & $f_{2}$ & $f_{3}$ & $f_{4}$ & \multirow{2}{*}{$\begin{array}{c}\text { h hierarchy } \\
\text { weight }\end{array}$} \\
\cline { 2 - 5 } & 0.575 & 0.276 & 0.097 & 0.052 & 0.412 \\
\hline$p_{1}$ & 0.595 & 0.082 & 0.429 & 0.105 & 0.49 \\
\hline$p_{2}$ & 0.275 & 0.237 & 0.429 & 0.637 & 0.298 \\
\hline$p_{3}$ & 0.130 & 0.681 & 0.142 & 0.258 & 0.290 \\
\hline
\end{tabular}

\section{Conclusions}

Scheme weights arrangement gets that organize cheerleading activities has stronger effects on promoting campus culture construction, secondly is cheerleading classroom language teaching. In view of comprehensive consideration, school should take classroom education as auxiliary, and take organizing cheerleading activities as primary to stimulate cheerleading construction effects on campus culture.
This reasearch is supported by the personalized teaching aerobics study (2015CE18) in 2015 research projects Huanggang Normal University. 2014 Hubei province project in humanities and social science: in the construction of urbanization path of the development of rural school sports research (14G383). 2015 Huanggang normal university research projects, rural school sports development path, based on the perspective of government purchasing public sports services (2015017003).

\section{References}

1. K. Wang, W. Y. Wei, China Sport Science, 25, 42-45(2005).

2. H. B. Li and H. Liu, Journal of Sports Adult Education, 27, 55-57(2011).

3. F. J. Yang, Journal of Beijing Sport University, 4(1998).

4. L. P. Dai, Fujian Sports Science and Technology, 31, 27-30(2012).

5. X. H. Shan, Y. S. Dai, G. J. Cai and J. C. Jin, Sports \& Science, 18, 22-26(1997).

6. H. H. Kwon, J. Y. Kim and B. H. Choi et al, Journal of Coastal Research, 1157-1161(2016).

7. D. Jhu, L. Xue and R. Rodriguez, Journal of Mechanical Engineering Research and Developments, 38, 148-154(2015).

\section{Acknowledgments}

